\title{
Patients with preeclampsia develop agonistic autoantibodies against the angiotensin $\mathrm{AT}_{1}$ receptor
}

\author{
Gerd Wallukat, ${ }^{1}$ Volker Homuth ${ }^{1}$, Thorsten Fischer ${ }^{2}$, Carsten Lindschau ${ }^{1}$, \\ Björn Horstkamp ${ }^{3}$, Axel Jüpner ${ }^{5}$, Evi Baur ${ }^{1}$, Eberhard Nissen ${ }^{3}$, Klaus Vetter ${ }^{4}$, \\ Dajana Neichel ${ }^{1}$, Joachim W. Dudenhausen ${ }^{3}$, Hermann Haller ${ }^{1}$, and Friedrich C. Luft ${ }^{1}$
}

${ }^{1}$ Franz Volhard Clinic at the Max Delbrück Center for Molecular Medicine, Humboldt University of Berlin, 13122 Berlin, Germany ${ }^{2}$ Department of Obstetrics and Gynecology, University of Erlangen-Nürnberg, 91054 Erlangen, Germany ${ }^{3}$ Department of Obstetrics, Virchow Klinikum-Charité, German Heart Institute, 13353 Berlin, Germany

${ }^{4}$ Department of Obstetrics, Krankenhaus Neukölln, 12051 Berlin, Germany

${ }^{5}$ Department of Obstetrics and Gynecology, Klinikum Buch, 13125 Berlin, Germany

Address correspondence to: Friedrich C. Luft, Franz Volhard Clinic, Wiltberg Straße 50, 13122 Berlin, Germany.

Phone: 49-30-9417-2202; Fax: 49-30-9417-2206; E-mail: luft@fvk-berlin.de

Received for publication May 26, 1998, and accepted in revised form February 23, 1999.

Immune mechanisms and the renin-angiotensin system are implicated in preeclampsia. We investigated 25 preeclamptic patients and compared them with 12 normotensive pregnant women and 10 pregnant patients with essential hypertension. Antibodies were detected by the chronotropic responses to $\mathrm{AT}_{1}$ receptor-mediated stimulation of cultured neonatal rat cardiomyocytes coupled with receptor-specific antagonists. Immunoglobulin from all preeclamptic patients stimulated the $\mathrm{AT}_{1}$ receptor, whereas immunoglobulin from controls had no effect. The increased autoimmune activity decreased after delivery. Affinity-column purification and anti-human IgG and IgM antibody exposure implicated an IgG antibody directed at the $\mathrm{AT}_{1}$ receptor. Peptides corresponding to sites on the $\mathrm{AT}_{1}$ receptor's second extracellular loop abolished the stimulatory effect. Western blotting with purified patient IgG and a commercially obtained $\mathrm{AT}_{1}$ receptor antibody produced bands of identical molecular weight. Furthermore, confocal microscopy of vascular smooth muscle cells showed colocalization of purified patient IgG and $A T_{1}$ receptor antibody. The protein kinase $\mathrm{C}(\mathrm{PKC})$ inhibitor calphostin $\mathrm{C}$ prevented the stimulatory effect. Our results suggest that preeclamptic patients develop stimulatory autoantibodies against the second extracellular $\mathrm{AT}_{1}$ receptor loop. The effect appears to be $\mathrm{PKC}$-mediated. These novel autoantibodies may participate in the angiotensin II-induced vascular lesions in these patients.

J. Clin. Invest. 103:945-952 (1999).

\section{Introduction}

Preeclampsia usually occurs after week 20 of gestation and features hypertension and an increased peripheral vascular resistance. The mechanisms are unknown (1). Several lines of evidence implicate angiotensin II (Ang II) and its binding site, the $\mathrm{AT}_{1}$ receptor. Preeclamptic patients manifest exaggerated pressor responses to Ang II. Gant et al. (2) infused Ang II into pregnant patients from week 10 of pregnancy onward and observed that those who later developed sustained hypertension required diminishing amounts of Ang II to obtain a similar pressor response. One possible explanation for this phenomenon might be increased expression of the $\mathrm{AT}_{1}$ receptor. Baker et al. (3) also performed Ang II infusion experiments in pregnant patients and identified five patients who subsequently developed hypertension after week 20 . These women were compared with seven who did not develop hypertension. The platelets of the preeclamptic women exhibited increased calcium signaling and increased binding sites for Ang II. The authors suggested increased stimulus-effect coupling in terms of Ang II responses in preeclamptic patients. We also observed increased cytosolic calcium responses in the platelets of preeclamptic patients in response to Ang II (4). However, circulating levels of Ang II are not increased in preeclampsia (5-7). In an earlier study of patients with essential hypertension, we observed a remarkably high incidence of circulating antibodies that cross-reacted with the $\alpha 1$-adrenoceptor and stimulated its signaling mechanism (8). In the present study, we tested the hypothesis that circulating antibodies to a vascular receptor might be responsible for the hypertension observed in preeclampsia. We employed a bioassay of beating neonatal rat cardiomyocytes, as well as Western blotting and confocal microscopy. We found that immunoglobulin from preeclamptic women contains a factor that binds to, and stimulates, the $\mathrm{AT}_{1}$ receptor.

\section{Methods}

Cell culture. Isolation and cultivation of neonatal heart cells were performed as described previously (9). Briefly, single cells were dissociated from the minced ventricles of Wistar rats (1-2 days old) with a $0.25 \%$ solution of crude trypsin and were cultured as monolayers with a density of 800 cells $/ \mathrm{mm}^{2}$ in Halle SM 20-I medium equilibrated with humidified air. The medium contained $10 \%$ heat-inactivated FCS and $2 \mu \mathrm{mol} / 1$ fluorodeoxyuridine (Serva, Heidelberg, Germany) the latter to prevent proliferation of nonmuscle cells. On the third or fourth days, the cells were incubated for $2 \mathrm{~h}$ in $2 \mathrm{ml}$ fresh serum-containing medium. Seven to 10 selected cells or synchronously contracting cell clusters per flask were counted for $15 \mathrm{~s}$. This procedure was 


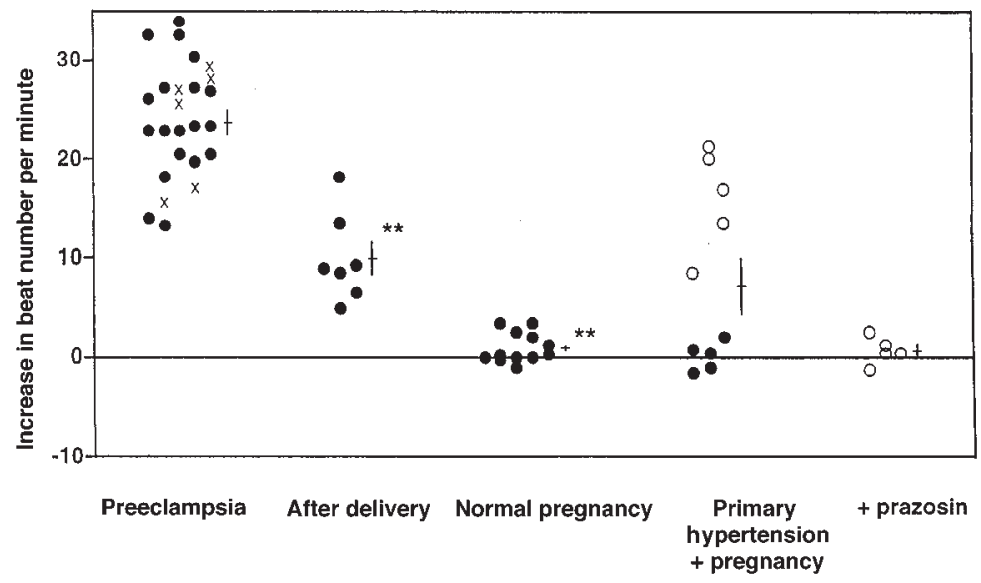

\section{Figure 1}

Increase in beat number of spontaneously beating neonatal rat cardiomyocytes when exposed to immunoglobulin from 25 patients with preeclampsia, 7 patients after delivery, and 12 patients with normal pregnancy. Nulliparous patients are shown with filled circles, while multiparous patients are designated with an $x$. Ten pregnant patients with essential hypertension were studied; five (open circles) had immunoglobulins that increased the beating rate. This increase was abolished by prazosin, implying involvement of the $\alpha 1$ adrenoceptor in these five patients. ${ }^{*}$ Different from preceding group $(P<0.01)$. repeated twice in different cultures to yield results representing a total of up to 30 cells for each sample. Immunoglobulin fractions, agonist and antagonist drugs, peptides, etc. were added singly or cumulatively as indicated. The basal contraction rate of the spontaneously beating cardiomyocytes was $162 \pm 4 \mathrm{~min}$.

Preparation of the immunoglobulin fraction. The immunoglobulin fraction was isolated from 1- to 2-ml serum samples by ammonium sulfate precipitation at a saturation of $40 \%$. The precipitates were washed and dissolved in dialysis buffer (154 $\mathrm{mmol} / \mathrm{l} \mathrm{NaCl}, 10 \mathrm{mmol} / 1$ sodium phosphate; $\mathrm{pH} 7.2$ ). The procedure of precipitating, washing, and dissolving was repeated twice. Finally, the immunoglobulins were taken up in $2 \mathrm{ml} \mathrm{PBS}\left(\mathrm{pH} 7.2\right.$ ) and dialyzed at $4^{\circ} \mathrm{C}$ for 30 hours against 11 of dialysis buffer. The buffer was changed five times during dialysis. Recently we also employed specific anti-human IgG columns, as well as protein A columns, and obtained similar results. For detection of autoantibodies, the immunoglobulin fractions were added at a dilution of 1:20 to the flasks. For the neutralization experiments, the synthetic peptide corresponding to the sequence of the second extracellular loop of the human $\mathrm{AT}_{1}$ receptor position 165-191 (I-H-R-N-V-F-FI-I-N-T-N-I-T-V-C-A-F-H-Y-E-S-Q-N-S-T-L) was added in excess $(0.5 \mu \mathrm{g}$ in $50 \mu \mathrm{l})$ to $50 \mu \mathrm{l}$ of the immunoglobulin fraction. The mixtures were shaken and placed in a refrigerator for $1 \mathrm{~h}$. The $100-\mu \mathrm{l}$ samples were then added to neonatal rat heart muscle cells cultured in $2 \mathrm{ml}$ medium to a final dilution of 1:40. The beating rate was counted for $15 \mathrm{~s}, 5 \mathrm{~min}$, and 60 min after the addition of the peptide/immunoglobulin mixture. Affinity purification was performed. The immunoglobulin fractions from the patients were loaded on a Sepharose 4B CNBr-activated gel (Pharmacia Biotech AB Uppsala, Sweden) to which the peptide corresponding to the second extracellular loop of the $\mathrm{AT}_{1}$ receptor was covalently linked. The antibodies were eluted with $3 \mathrm{M}$ potassium thiocyanate $(\mathrm{pH}$ 7.4) followed by immediate extensive dialysis against PBS.

Immunocytochemistry and Western blotting. Rat aortic vascular smooth muscle cells (VSMCs) were obtained as described earlier (10). The cells were fixed with $4 \%$ paraformaldehyde and permeabilized with $80 \%$ methanol at $-20^{\circ} \mathrm{C}$. We used commercially available antibodies directed against the $\mathrm{AT}_{1}$ receptor (Santa Cruz Biotechnology Inc., Santa Cruz, California, USA). Cells were then exposed to the secondary antibody (Cy2- and Cy3conjugated anti-rabbit or anti-human IgG, at 1:100, $1 \%$ BSA/PBS; Dianova, Hamburg, Germany) for $60 \mathrm{~min}$. The preparation was mounted with $50 \%$ glycerol under a glass coverslip on a Nikon-Diaphot microscope (Nikon Tokyo, Japan). A Bio-Rad MRC 600 confocal imaging system (Bio-Rad Laboratories, Munich, Germany) with an argon/krypton laser was used. At least 10-18 cells from each of at least four experiments were examined under each experimental condition. The results were reproduced by two separate investigators and multiple experiments were done. The observers were unaware of the experimental design and antibodies used.

Western blot analysis was carried out as described previously (10). After the experiments, the VSMCs were exposed to either affinity-purified IgG fractions or antibodies directed against the $\mathrm{AT}_{1}$ receptor (see above) diluted in incubation buffer. A final incubation was carried out in Tris-buffered saline (TBS) with peroxidase-conjugated anti-rabbit or anti-human IgG (Pierce Chemicals, Oud-Beijerland, the Netherlands). The results were viewed by chemiluminescence (Renaissance; Du Pont NEN Research Products, Boston, Massachusetts, USA)

Patients. Forty-eight pregnant women were recruited from the Departments of Obstetrics and Gynecology of the University of Erlangen-Nürnberg, the University Hospital Virchow Klinikum-Charité, and city hospitals in Buch and Neukölln (Berlin, Germany). Twenty-five women had preeclampsia defined by hypertension and proteinuria after week 20 of pregnancy; 19 were delivering for the first time, while 6 were multiparous (1). One of these women had essential hypertension and developed superimposed preeclampsia manifested as proteinuria and worsened hypertension after week 20 of pregnancy. Hypertension was defined as a blood pressure of $\geq 140 / 90 \mathrm{mmHg}$ after week 20 of pregnancy. Proteinuria was defined as "a positive reading" from a random urine sample or $\geq 300 \mathrm{mg}$ in a 24 -h urine collection. The preeclampsia group ranged in age from $21-37$ years (mean age: 29 years). The 12 nonpreeclamptic healthy pregnant patients ranged in age from 21-32 years (mean age: 27 years). Ten age-matched pregnant women with preexisting essential hypertension, aged 20-40 years (mean age: 32 years), were also studied. All women gave written, informed consent as determined by our committee on human subjects. For serum preparation, the samples were centrifuged at $4,000 \mathrm{~g}$ for $30 \mathrm{~min}$ and stored at $-20^{\circ} \mathrm{C}$.

Reagents. Prazosin was purchased from Sigma-Aldrich Chemie (Deisenhofen, Germany), and losartan was obtained from Merck Sharp \& Dohme (Munich, Germany). All other chemicals were of analytical grade. PD 123319 was donated by Parke-Davis Co. (Ann Arbor, Michigan, USA)

Statistics. Results are expressed as the means \pm SEM. Student's $t$ test was used to compare variables between the groups. Values of $P<0.05$ are significant.

\section{Results}

Figure 1 shows the increase in beats per minute (bpm) of spontaneously beating neonatal rat cardiomyocytes when exposed to immunoglobulin from 25 patients with 
$a$

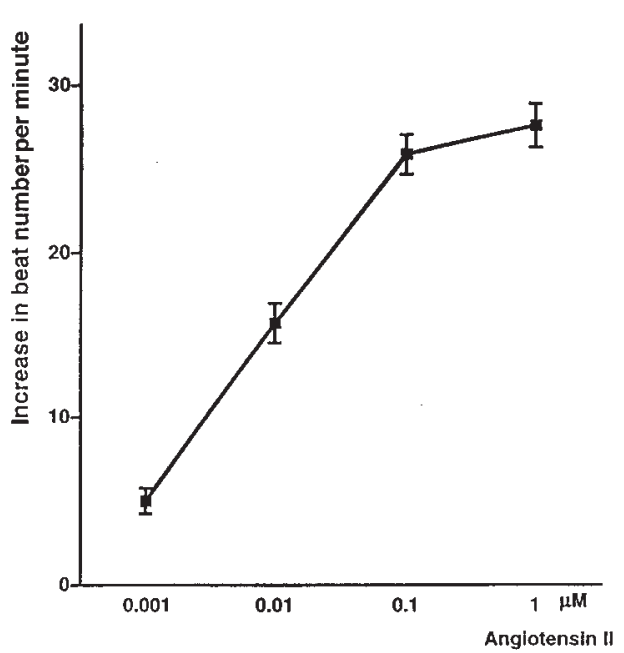

$\boldsymbol{b}$

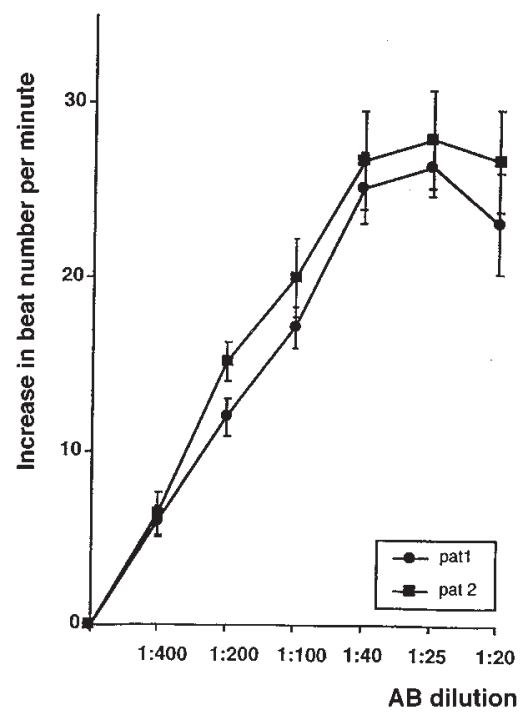

Figure 2

(a) Dose-response relationship between Ang II concentrations and spontaneous beating rate. A plateau was observed after $0.1 \mu \mathrm{M}$. (b) Dose-response relationship of immunoglobulin fractions from two preeclamptic women (each measured 10 times) on the spontaneous beating rate. Dilutions from 1:20 to $1: 400$ were prepared. A linear response from 1:400 to 1:40 was observed, after which a maximum effect was observed. Ang II, angiotensin II.

preeclampsia, 7 patients after delivery, 12 patients with normal pregnancies, and hypertensive patients who became pregnant. Preeclamptic immunoglobulin increased the beat number by $23 \mathrm{bpm}$, which was different from immunoglobulin from women with normal pregnancies $(P<0.01)$ and similar to the effect of $0.1 \mu \mathrm{M}$ Ang II (see below). Seven preeclamptic women were studied after delivery. Their serum affected the spontaneous beating rate; however, the rate had decreased by $50 \%$ but remained above control levels $(P<0.01)$. The postpartum samples were obtained on days 5, 6, 7, 9, and 29 after delivery. We do not have sufficient data for later time points, particularly between days 9 and 29, to calculate an accurate half-life. The immunoglobulin samples from 5 of 10 hypertensive pregnant, but nonpreeclamptic, patients appeared to contain a fraction that interacted with the $\alpha 1$-adrenoceptor, as we described earlier (8). These five women had immunoglobulin that increased the beats per minute by 10 ; however, the addition of prazosin abolished this increase.

We next studied the effect of Ang II directly on the spontaneous beating rate and observed a dose-response relationship as shown in Figure $2 a$. At concentrations between 0.001 and $0.1 \mu \mathrm{M}$, a dose-dependent increase in the spontaneous beating rate was observed, which leveled off at higher concentrations. This effect was selectively blocked by losartan but not by the $\mathrm{AT}_{2}$ receptor blocker PD 123319 (not shown). A dose-response curve from the immunoglobulin fraction from two preeclamptic patients is shown in Figure $2 b$. A linear response from dilutions of 1:400 to 1:40 was observed. The response was maximal at a dilution of 1:40, and increasing the concentration further did not increase the response. Again, 10 separate measurements were performed at each dilution from both patients. Figure 3 shows the effects of angiotensin receptor blockade with PD 123319 directed against the $\mathrm{AT}_{2}$ receptor and losartan directed against the $\mathrm{AT}_{1}$ receptor, as well as the combination of losartan and prazosin, on the increase in beat number induced by immunoglobulin from preeclamptic patients. Immunoglobulin samples from 10 preeclamptic patients were studied. Immunoglobulin from all preeclamptic patients increased the beats per minute by 20-27. PD 123319 had no effect, indicating that the $\mathrm{AT}_{2}$ receptor was not involved in the responses. Losartan abolished the increase in beats per minute completely in five of the samples tested and reduced the beats per minute by two-thirds in five of the remaining samples. In these samples, the increase was abolished by prazosin. These responses raised the possibility that immunoglobulin from preeclamptic patients contains a fraction that increases the spontaneous cardiomyocyte beat frequency through an interaction with the $\mathrm{AT}_{1}$, but not the $\mathrm{AT}_{2}$, receptor. Furthermore, in half of the patients, an additional $\alpha 1$-adrenergic response was identified.

We next tested the specificity of the response by preincubating the immunoglobulin from the preeclamptic patients with a peptide consisting of the second extracellular loop of the $\mathrm{AT}_{1}$ receptor, as shown in Figure 4. This maneuver decreased the stimulatory effect on cardiomyocyte beat frequency from 25 to $8 \mathrm{bpm}$. Adding prazosin abolished the residual stimulatory effect. To rule out a nonspecific peptide effect, we preincubated the patients' immunoglobulin with a peptide consisting of the second extracellular loop of the $\beta_{1}$-adrenergic receptor. This peptide had no effect on the spontaneous beating rate. The responses indicate inhibition of antibody directed against the $\mathrm{AT}_{1}$ receptor by the peptide, thereby verifying the specificity of the response. A residual response mediated by the $\alpha_{1}$-adrenergic receptor was abolished by the addition of prazosin.

We then tested immunoglobulins from five patients who were preexposed to peptides containing the amino acid sequence of the first, second, and third extracellular $\mathrm{AT}_{1}$ receptor loops (data not shown). Only peptides from the second extracellular loop blocked the effect. We next added anti-human IgG and anti-human IgM antibody to the 


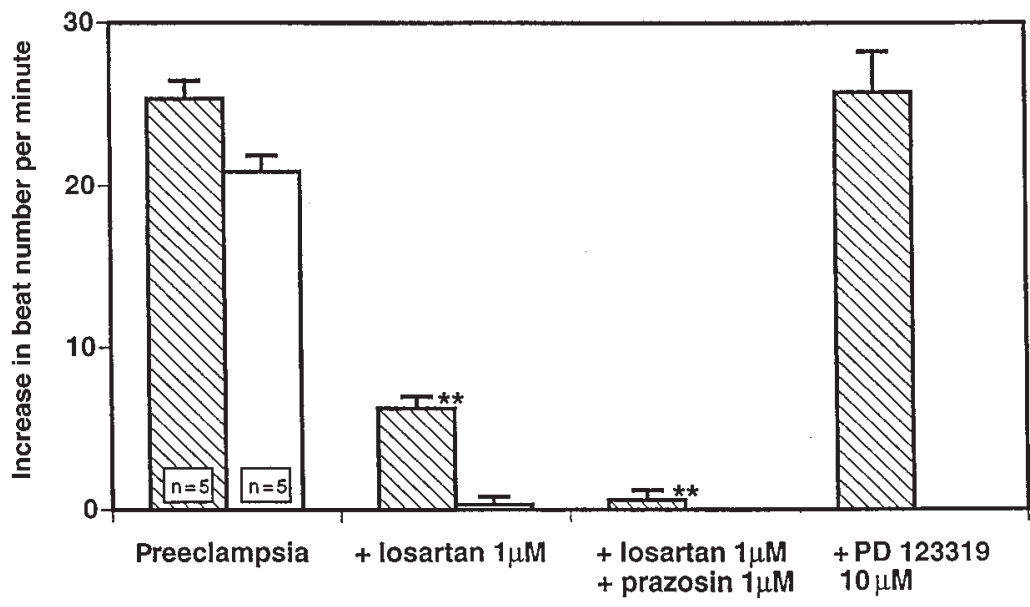

\section{Figure 3}

Increase in beat number induced by immunoglobulin from patients with preeclampsia, complete inhibition of the response by losartan (five patients; open bars), and additional inhibition by prazosin (five patients; hatched bars). The responses indicate primary involvement of the $\mathrm{AT}_{1}$ receptor and an additional response involving the $\alpha_{1}$ adrenoceptor. The specificity of the $\mathrm{AT}_{1}$ response is shown, in that the $A_{2}$ receptor blocker $P D$ 123319 had no effect on any of the responses.

immunoglobulin fraction from seven preeclamptic patients. The anti-human IgG antibody abolished the effect, whereas the anti-human IgM antibody had no effect (data not shown). These results support the notion that an IgG antibody in the immunoglobulin fraction from preeclamptic women was responsible for the effect. We used the affinity column-purified material to reexamine possible epitopes on the second loop of the $\mathrm{AT}_{1}$ receptor. Figure 5 shows the effects of short, overlapping peptides corresponding to the second extracellular loop of the $\mathrm{AT}_{1}$ receptor. Only the amino acid sequence AFHYESQ abolished the increase in the spontaneous beating rate in all nine patients tested. These findings suggest that this site contains the binding epitopes of the antibody.

In Figure 6, we show Western blot bands produced by commercially available $\mathrm{AT}_{1}$ receptor antibody (Figure 6a). Two bands are seen, probably corresponding to the glycosylated and nonglycosylated forms of the receptor. The same bands appear (Figure 6b) in a Western blot using affinity column-purified IgG from preeclamptic patient serum. Identically handled serum from nonpreeclamptic patients produced no bands. Confocal photomicrographs (representative of four experiments) of VSMCs exposed to affinity column-purified IgG from preeclamptic patient serum and commercially available $\mathrm{AT}_{1}$ receptor antibody are shown in Figure 7. A Cy3-labeled anti-human IgG antibody produced the red staining (Figure $7 a$; left). The same cells were then exposed to commercially available $\mathrm{AT}_{1}$ receptor antibody (Figure 7a; center) with a Cy2-labeled secondary anti-human IgG antibody. Superimposition (Figure $7 a$; right) revealed that these antibodies colocalized. The bottom panels of Figure 7 show the same procedure with an IgG fraction from a pregnant, nonpreeclamptic patient. Only staining from the commercially available $\mathrm{AT}_{1}$ receptor antibody is seen.

Finally, as shown in Figure 8, we tested to see if the responses were mediated by protein kinase $\mathrm{C}$ (PKC). We first observed an increase in beat number induced by immunoglobulin from four patients (10 separate measurements each) with preeclampsia, followed by PKC inhibition with calphostin C. Calphostin $\mathrm{C}$ resulted in elimination of the increased beating response in 30 minutes.

\section{Discussion}

Our data suggest that immunoglobulin extracted from the serum of preeclamptic patients contains an antibody that binds to the $\mathrm{AT}_{1}$ receptor and has agonist activity. The antibody subsides after the pregnancy is terminated. Affinity-column purification and exposure to antihuman IgG and IgM antibodies provide evidence that an IgG autoantibody to the $\mathrm{AT}_{1}$ receptor is involved. Binding to the second loop of the $\mathrm{AT}_{1}$ receptor was implicated by the results of our second loop-containing peptide experiment. Specificity was further supported by the exposure to short, overlapping peptides of the second extracellular loop. A lesser antibody response directed

\section{Figure 4}

Increase in beat number induced by immunoglobulin from patients with preeclampsia, the response after preexposure of the immunoglobulin to a peptide consisting of the second extracellular loop of the $\mathrm{AT}_{1}$ receptor, and additional inhibition by prazosin. The response indicates inhibition of antibody directed against the $A T_{1}$ receptor by the peptide, thereby verifying the specificity of the response. We included a control peptide consisting of the second extracellular loop of the $\beta 1$-adrenergic receptor. This peptide had no effect on the spontaneous beating rate.

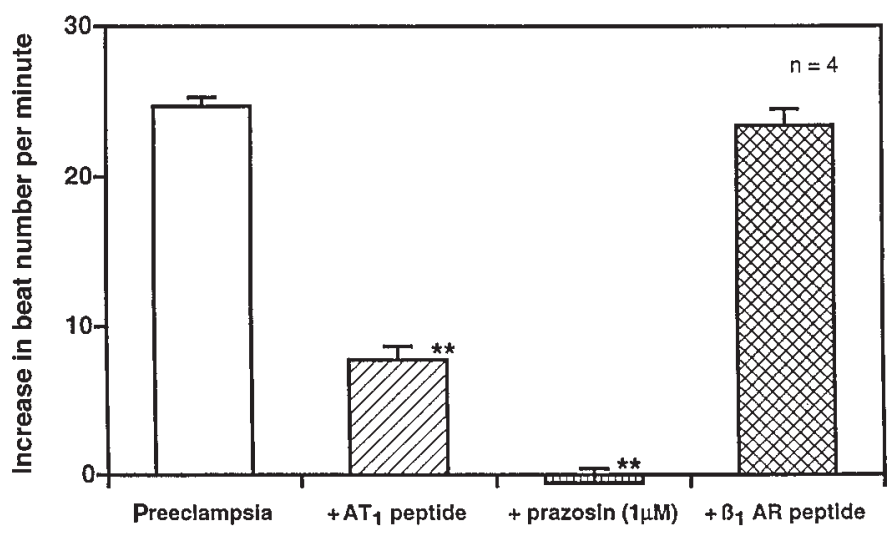




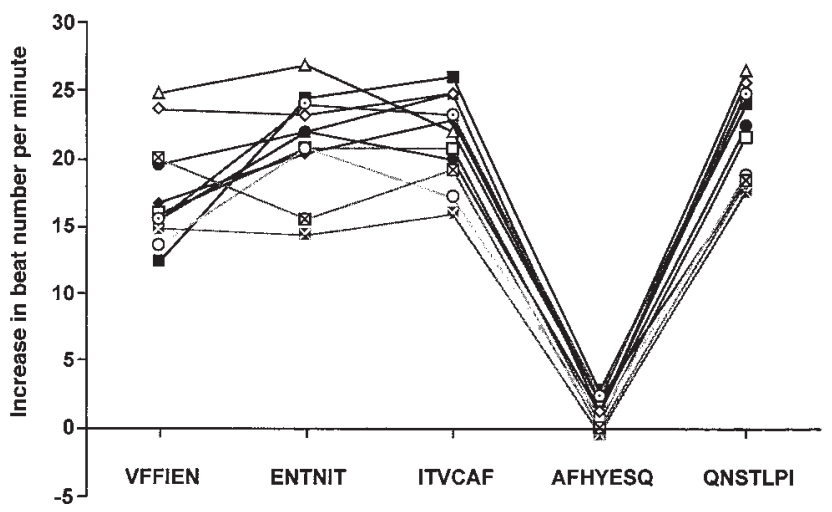

Figure 5

Short, overlapping peptides corresponding to the second extracellular loop of the $\mathrm{AT}_{1}$ receptor were prepared. These peptides were exposed to affinity-purified antibody preparations. We tested the effect on the spontaneous beating rate of neonatal rat cardiomyocytes. The sequence AFHYESQ abolished the response.

against the $\alpha 1$-adrenoceptor was detected in some of the women. Pregnant women with preexisting hypertension did not have antibody against the $\mathrm{AT}_{1}$ receptor; however, some had antibody activity directed at the $\alpha_{1}$-adrenergic receptor, consistent with our earlier findings (8). We were able to identify an $\mathrm{AT}_{1}$ receptor antibody, independent of our bioassay, by means of Western blotting and confocal microscopy in VSMCs. Finally, preliminary observations with the PKC inhibitor calphostin $\mathrm{C}$ documented the intracellular signaling and suggested that the postreceptor signaling mechanism involves PKC. Our findings raise the possibility that these antibodies may be of mechanistic importance in preeclampsia.

The renin-angiotensin system has been implicated in preeclampsia. Gant et al. (2) identified hypersensitivity to infused Ang II in preeclamptic patients, although the angiotensin sensitivity test in preeclampsia is not invariably positive (11). Calcium signaling is increased in preeclamptic patients, with increased Ang II binding sites on platelets (3). Sowers et al. (12) found elevated active tissue renin concentrations and increased renin mRNA expression in placentas from preeclamptic patients, compared with placentas from women with normal pregnancies. In their study, angiotensinogen tissue concentrations and angiotensinogen mRNA expression were not different between the two groups. Brar et al. (13) reported somewhat similar findings. They observed increased chorionic tissue active renin levels in patients with preeclampsia, compared with controls. These results are consistent with the reduced placental perfusion implicated in the pathogenesis of preeclampsia (14).

Another line of evidence implicating the reninangiotensin system in preeclampsia stems from genetic observations. A familial tendency toward preeclampsia has been observed by several groups $(15,16)$. Ward et al. (17) reported a significant association between preeclampsia and the angiotensinogen variant T235 in both Caucasian and Japanese subjects. Inoue et al. (18) subsequently observed a mutation leading to the replacement of leucine by phenylalanine at position 10 of mature angiotensinogen (L10F), the site of renin cleavage, in a preeclamptic patient. This mutation significantly alters the reactions of angiotensinogen with both renin- and angiotensin-converting enzyme. As a result, the catalytic efficiency is doubled. Inoue et al. suggested that the L10F mutation might facilitate the development of preeclampsia.

Autoantibodies directed at receptors are important in myasthenia gravis (19) and Graves' disease (20). In Graves' disease, the antibodies exhibit agonist activity. A further example that antibodies can activate receptors is the demonstration that a monoclonal antibody was able to activate the mutant insulin receptor Ser323Leu, which is responsible for the Rabson-Mendenhall syndrome (21). We have identified autoantibodies directed against the $\beta 1$-adrenoceptor in patients with dilatative cardiomyopathy $(9,22)$ and against the $\alpha 1$-adrenoceptor in patients with malignant hypertension (23). Anti-AT 1 autoantibodies have been described previously in patients with malignant hypertension (24). The notion that such autoantibodies are clinically important is supported by the finding that patients with dilatative cardiomyopathy and anti- $\beta 1$-adrenoceptor autoantibodies improved with

\section{Figure 6}

Western blot (representative of 4 experiments) of vascular smooth muscle cell (VSMC) extract. Column (a) shows bands (arrows) produced by a commercial antibody directed against the $A T_{1}$ receptor. Column $(\boldsymbol{b})$ shows bands produced by column-purified IgG from preeclamptic patients. Column (c) shows identically handled column-purified IgG from nonpreeclamptic pregnant patients. Two bands are probably the result of glycosylated and nonglycosylated forms of the receptor.

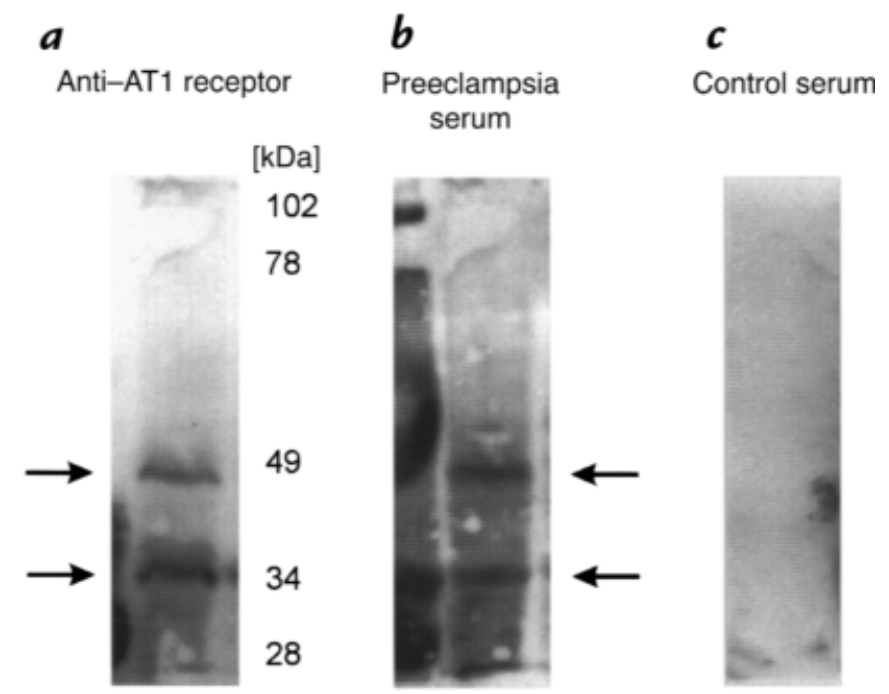




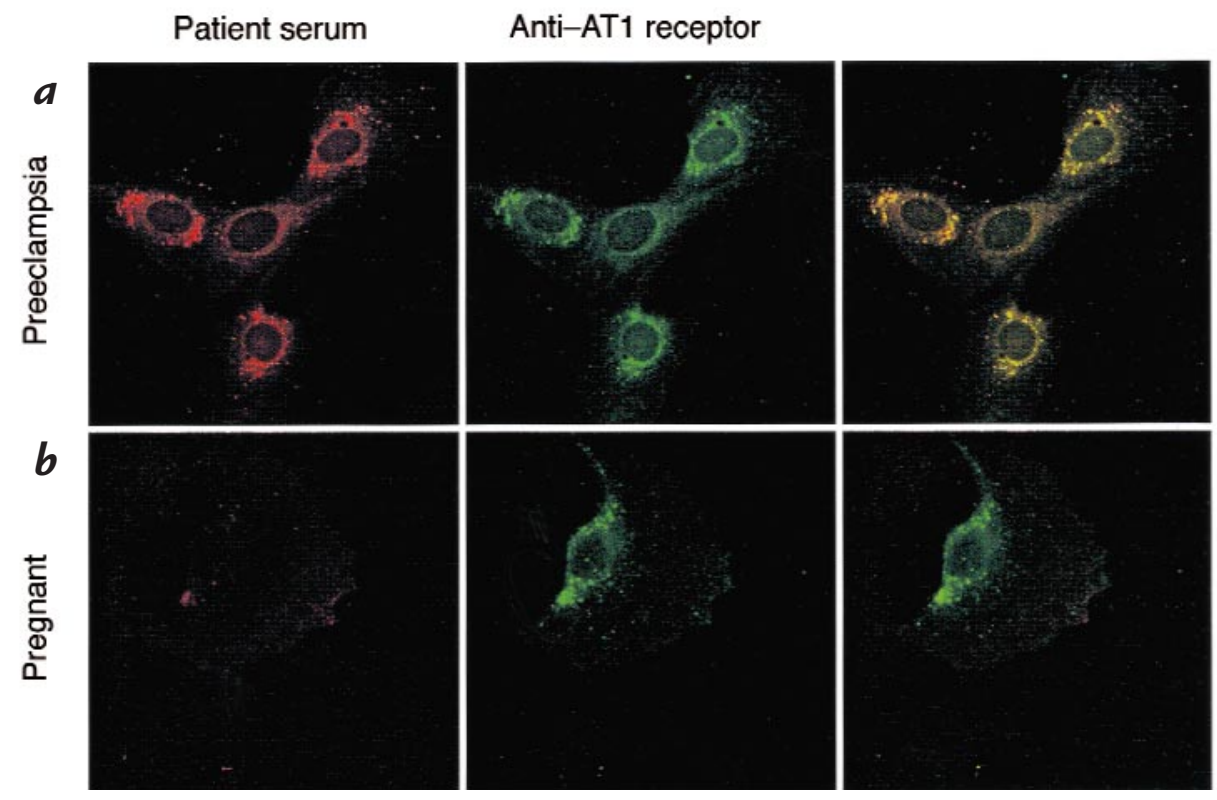

Figure 7

Confocal photomicrograph (representative of four experiments) of VSMCs exposed to affinity column-purified IgG from preeclamptic patient serum and commercially available $\mathrm{AT}_{1}$ receptor antibody. (a) A Cy3-labeled anti-human IgG antibody produced the red staining (left). The same cells were simultaneously exposed to commercially available $\mathrm{AT}_{1}$ receptor antibody (center) with a Cy2-labeled secondary anti-human IgG antibody. Superimposition (right) revealed that these antibodies colocalize (yellow). (b) The same procedure with IgG fraction from a pregnant nonpreeclamptic patient. Only staining from the commercially available $\mathrm{AT}_{1}$ receptor antibody is seen.

immunoadsorption (25). Finally, in cardiomyopathy patients treated with a left ventricular assist device, improvement in cardiac function was associated with a decrease in anti- $\beta 1$-adrenoceptor autoantibodies (26).

The fact that we were able to eliminate a chronotropic effect of immunoglobulin from preeclamptic patients by prior incubation with peptide segments contained in the second extracellular loop of the $\mathrm{AT}_{1}$ receptor is a strong argument in support of the notion that the autoantibodies bind at these sites to the receptor in vivo. A threedimensional model of the $\mathrm{AT}_{1}$ receptor proposed by Inoue et al. (27) suggests that Ang II binding may cause each helix of the receptor to undergo appreciable rotation to form bonding between transmembrane domain 7 and transmembrane domain 2 . Such bonding would constrain the receptor to adopt a unique conformation that Inoue et al. termed the "agonist-bound" conformation. This conformation then promotes $G$ protein-coupled signaling. We suggest that the autoantibodies are directed at extracellular loop 2 sites and activate the receptor similar to its natural agonist, Ang II. The activation may involve a cross-link between receptors that holds the receptors in their activated conformation $(28,29)$. We have unpublished preliminary evidence from experiments using $\mathrm{F}(\mathrm{ab})$ fragments that such is the case for the $\beta 1$-adrenoceptor autoantibodies, which we have described previously in patients with dilatative cardiomyopathy (24). However, alternative possibilities also warrant consideration. Conceivably, interaction of the autoantibody with the $\mathrm{AT}_{1}$ receptor alters the configuration such that the receptor is more likely to be occupied by Ang II. Ang II is undoubtedly present in the culture media used for rat neonatal cardiomyocytes. Furthermore, evidence has been presented that neonatal car- diomyocytes may produce their own Ang II, independent of renin (30). Such an explanation would be more consistent with the earlier findings of Gant et al. (2).

Preeclampsia is associated with abnormal placentation, reduced placental perfusion, endothelial cell dysfunction, and systemic vasospasm. An immune mechanism has long been postulated (31). Increased prevalence in multiple and molar pregnancies, and those associated with increased placental mass, suggests that trophoblastic volume and fetal antigen load are correlated with the syndrome. Kupferminc et al. (32) found that tumor necrosis factor- $\alpha$ is increased in the plasma and amniotic fluid of patients with preeclampsia, which is consistent with abnormal immune activation. Hara et al. (33) demonstrated the presence of interleukin- 2 in decidua cells of patients with preeclampsia, also consistent with an enhanced immune response. Autoimmune mechanisms have been postulated, including autoantibodies directed against certain types of phospholipids or trophoblastic constituents (34). As a result, corticosteroid therapy has been applied in severe preeclampsia, with encouraging preliminary results (35).

We can only speculate on the mechanisms responsible for the production of $\mathrm{AT}_{1}$ receptor antibodies in preeclampsia. The $\mathrm{AT}_{1}$ receptor appears to be upregulated in preeclampsia. We and others have found that circulating factors are directed against endothelial cells in preeclampsia and cause their activation (36). We were recently able to show that such a factor is responsible for a marked increase in endothelial permeability and that the mechanism is also PKC-mediated (37). Whether or not this factor and the autoantibodies we describe here are one and the same has yet to be proved; however, Ang II is known to have a permeabilizing effect on endothe- 


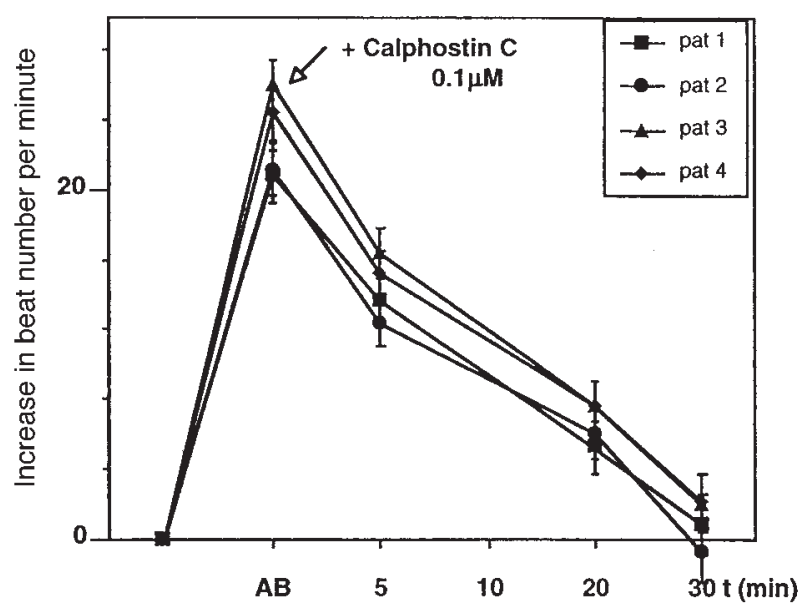

Figure 8

Increase in beat number induced by immunoglobulin from four patients with preeclampsia followed by protein kinase $\mathrm{C}$ inhibition with calphostin C. Calphostin C resulted in elimination of the response in $30 \mathrm{~min}$.

lium (38). Maybe such preeclampsia-associated factors are related to a disorderly receptor upregulation and subsequent autoantibody production. $\mathrm{AT}_{1}$ receptor production, in contrast to other components of the renin-angiotensin system (11), has not been studied in placental tissue to our knowledge. Conceivably, diminished placental perfusion could alter $\mathrm{AT}_{1}$ receptor expression in an aberrant fashion, thereby permitting autoantibody production.

A number of our observations remain unexplained. The $\mathrm{AT}_{1}$ receptor antibody dissipates rapidly after delivery, perhaps faster than can be explained by the half-life of IgG, which ranges from about 7 to 21 days, depending on the fraction. However, if complexes are formed, the disappearance may be faster. The postdelivery samples we have examined ranged between one and four weeks postpartum. Genuine preeclampsia is said to be a disease of first pregnancies, although the protective effect of multiparity is lost with change of partner (39). This observation raises the possibility of immune maladaptation. We had six multiparous women in our study and did not specifically inquire about or test for change of partner.

We are also not able to state for certain what the role of activating $\mathrm{AT}_{1}$ receptor antibodies might be in terms of explaining the clinical features of the preeclampsia syndrome, nor can we state how the antibodies are elicited. In a single patient (not shown), we happened to have a serum specimen at week 21 of pregnancy, while proteinuria and elevated blood pressure first developed at week 24 . At week 21, this patient had no $\mathrm{AT}_{1}$ receptor antibodies. At week 24, antibodies were readily detectable and peaked at week 26 , at which time delivery was induced. We made serial measurements after week 26 and observed abatement of the antibodies over six weeks. This patient's course suggests that $\mathrm{AT}_{1}$ receptor antibodies first manifest themselves shortly before the development of clinical symptoms. However, the conditions leading to preeclampsia may be established considerably earlier.

Zhou and colleagues (40) recently reported that human cytotrophoblasts adopt a vascular phenotype as they differentiate, which appears to be necessary for successful endovascular invasion. This development occurs in first half of pregnancy. They further observed that in preeclampsia, human cytotrophoblasts fail to express this vascular phenotype (41). Consequently, integrins, cadherins, immunoglobulin superfamily members, and perhaps other structures including surface receptors, are not produced appropriately. Whether or not maldeveloped cytotrophoblastic endovascular invasion, with compromised blood flow to the maternal-fetal interface, leads to immunogenic structures is unknown. Local concentrations of growth factors, including vascular endothelial growth factor (VEGF), are probably required for the conversion of extravascular cells to endothelium (42). Interestingly, Ang II interacts with VEGF and is able to increase its angiogenic activity (43).

Our observations are preliminary. The autoantibody-receptor interaction must be studied in much greater detail. Our precipitation experiments are a step in this direction. The signaling pathway elicited by the autoantibodies, including precise receptor conformation, must be elucidated in greater detail. Mutagenesis studies will be required to realize that goal. The clinical relevance of our findings will require clarification. Our hope is to offer preeclamptic patients improved options, particularly in terms of fetal growth and infant survival. A strategy of autoantibody removal might be a step in that direction.

\section{Acknowledgments}

This study was supported by grants-in-aid from the Deutsche Forschungsgemeinschaft (to H. Haller) and the Biomed Project of the European Community (to G. Wallukat).

1. Lindheimer, M.D. 1993. Hypertension in pregnancy. Hypertension. 22:127-137.

2. Gant, N.F., Daley, G.L., Chand, S., Whalley, P.J., and MacDonald, P.C. 1973. A study of angiotensin II pressor response throughout primigravid pregnancy. J. Clin. Invest. 52:2683-2689.

3. Baker, P.N., Kilby, M.D., and Pipkin, F.B. 1992. The effect of angiotensin II on platelet intracellular free calcium concentration in human pregnancy. J. Hypertens. 10:55-60.

4. Haller, H., Oeney, T., Hauck, U., Distler, A., and Philipp, T. 1989. Increased intracellular free calcium and sensitivity to angiotensin II in platelets of preeclamptic women. Am. J. Hypertens. 2:238-243.

5. Pipkin, F.B. 1988. The renin-angiotensin system in normal and hypertensive pregnancies. In Handbook of bypertension. Vol. 10. P.C. Rubin, editor. Elsevier Science Publishers. Amsterdam, the Netherlands. 118-151.

6. Hanssens, M., Keirse, M., Spitz, B., and Van Assche, F.A. 1991. Angiotensin II levels in hypertensive and normotensive pregnancies. $B r$. J. Obstet. Gynaecol. 98:155-161.

7. Hannsens, M., Keirse, M., Spitz, B., and Van Assche, F.A. 1991. Measurement of individual plasma angiotensins in normal pregnancy and pregnancy-induced hypertension. J. Clin. Endocrinol. Metab. 73:489-494.

8. Luther, H.-P., Homuth, V., and Wallukat, G. 1996. $\alpha 1$-adrenergic receptor antibodies in patients with primary hypertension. Hypertension. 29:678-682.

9. Wallukat, G., and Wollenberger, A. 1987. Effects of the serum gamma globulin fraction of patients with allergic asthma and dilated cardiomyopathy on chronotropic $\beta$-adrenoceptor function in cultured rat heart myocytes. Biomed. Biochim. Acta. 78:634-639.

10. Haller, H., et al. 1998. Integrin-induced PKC $\alpha$ and $\varepsilon$ translocation to focal adhesions mediates vascular smooth muscle cell spreading. Circ. Res. 82:157-165.

11. Kyle, P.M., Buckley, D., Kissane, J., de-Swiet, M., and Redman, C.W. 1995. The angiotensin sensitivity test and low-dose aspirin are ineffective methods to predict and prevent hypertensive disorders in nulliparous pregnancy. Am. J. Obstet. Gynecol. 173:865-872.

12. Sowers, J.R., et al. 1993. Expression of renin and angiotensinogen genes in preeclamptic and normal human placental tissue. Clin. Exp. Hypertens. B. 12:163-171. 
13. Brar, H.S., et al. 1987. Increased fetoplacental active renin production in pregnancy-induced hypertension. Am. J. Obstet. Gynecol. 157:363-367.

14. Roberts, J.M., and Redman, C.W.G. 1993. Pre-eclampsia: more than pregnancy-induced hypertension. Lancet. 341:1446-1451.

15. Chesley, L.C. 1980 . Hypertension in pregnancy: definitions, familial factor, and remote prognosis. Kidney Int. 18:234-250.

16. Cooper, D.W., Hill, J.A., Chesley, L.C., and Bryans, C.I. 1988. Genetic control of susceptibility to eclampsia and miscarriages. Br.J. Obstet. Gynaecol. 95:644-653.

17. Ward, K., et al. A molecular variant of angiotensinogen associated with preeclampsia. Nat. Genet. 4:59-61.

18. Inoue, I., et al. 1995. A mutation of angiotensinogen in a patient with preeclampsia leads to altered kinetics of the renin-angiotensin system. $J$. Biol. Chem. 270:11430-11436.

19. Almon, R.R., Andrew, C.G., and Appel, J.H. 1974. Serum globulin in myasthenia gravis: inhibition of $\alpha$-bungarotoxin binding to acetylcholine receptors. Science. 186:55-57.

20. Kishihara, M., et al. 1979. Interaction between thyroid-stimulating immunoglobulins and thyrotropin receptors in fat cell membranes. $J$. Clin. Endocrinol. Metab. 49:706-711.

21. Krook, A., Soos, M.A., Kumar, S., Siddle, K., and O'Rahilly, S. 1996. Functional activation of mutant human insulin receptor by monoclonal antibody. Lancet. 347:1586-1590

22. Magnusson, Y., Wallukat, G., Waagstein, F., Hjalmarson, A., and Hoebeke, J. 1994. Autoimmunity in idiopathic dilated cardiomyopathy: characterization of antibodies against the $\beta 1$-adrenoceptor with positive chronotropic effect. Circulation. 89:2760-2767.

23. Fu, M.L., et al. 1994. Functional autoimmune epitope on $\alpha 1$-adrenergic receptors in patients with malignant hypertension. Lancet. 334:1660-1663.

24. Fu, M.L., Herlitz, H., Wallukat, G., and Hjalmarson, A. 1996. Non-desensitized positive chronotropic effect of anti-angiotensin II receptor autoantibodies in patients with malignant hypertension. Circulation. 94:4046a. (Abstr.)

25. Dörffel, W.V., et al. 1997. Short-term hemodynamic effects of immunoadsorption in dilated cardiomyopathy. Circulation. 95:1994-1997.

26. Müller, J., et al. 1997. Weaning from mechanical cardiac support in patients with idiopathic dilated cardiomyopathy. Circulation. 96:542-549.

27. Inoue, Y., Nakamura, N., and Inagami, T. 1997. A review of mutagenesis studies of angiotensin II type 1 receptor, the three-dimensional recepto model in search of the agonist and antagonist binding site and the hypothesis of a receptor activation mechanism. J. Hypertens. 15:703-714.

28. Hebert, T.E., et al. 1996. A peptide derived from a beta2-adrenergic recep- tor transmembrane domain inhibits both receptor dimerization and activation. J. Biol. Chem. 271:16384-16392.

29. Elies, R., et al. 1998. Immunochemical and functional characterization of an agonist-like monoclonal antibody against the MS acetylcholine receptor. Eur. J. Biochem. 251:659-666.

30. Sadoshima, J., Xu, Y., Slayter, M.S., and Izumo, S. 1993. Autocrine release of angiotensin II mediates stretch-induced hypertrophy of cardiac myocytes in vitro. Cell. 75:977-984.

31. Taylor, R.N. 1997. Review: immunobiology of preeclampsia. Am. J. Reprod. Immunol. 37:79-86.

32. Kupferminc, M.J., Peaceman, A.M., Wigton, T.R., Rehnberg, K.A., and Socol, M.L. 1994. Tumor necrosis factor-alpha is elevated in plasma and amniotic fluid of patients with severe preeclampsia. Am. J. Obstet. Gynecol. 170:1752-1757.

33. Hara, N., Fujii, T., Okai, T., and Taketani, Y. 1995. Histochemical demonstration of interleukin- 2 in decidua cells of patients with preeclampsia. Am. J. Reprod. Immunol. 34:44-51.

34. Vinatier, D., and Monnier, C. 1995. Preeclampsia: physiology and immunological aspects. Eur. J. Obstet. Gynecol. Reprod. Biol. 61:85-97.

35. Magann, E.F., et al. 1994. Postpartum corticosteroids: accelerated recovery from the syndrome of hemolysis, elevated liver enzymes, and low platelets (HELLP). Am. J. Obstet. Gynecol. 171:1154-1158.

36. Roberts, J.M., Taylor, R.N., and Goldfien, A. 1991. Clinical and biochemical evidence of endothelial cell dysfunction in the pregnancy syndrome preeclampsia. Am. J. Hypertens. 4:700-708.

37. Haller, H., et al. 1998. Endothelial cell permeability and protein kinase C in preeclampsia. Lancet. 351:945-949.

38. Plante, G.E., Chakir, M., Ettaouil, K., Lehoux, S., and Sirois, P. 1996. Consequences of alteration in capillary permeability. Can. J. Physiol. Pharmacol. 74:824-833

39. Dekker, G.A., Robillard, P.Y., and Hulsey, T.C. 1998. Immune maladaptation in the etiology of preeclampsia: a review of corroborative epidemiologic studies. Obstet. Gynecol. Surv. 53:377-382.

40. Zhou, Y., et al. 1998. Human cytotrophoblasts adopt a vascular phenotype as they differentiate. J. Clin. Invest. 99:2139-2151.

41. Zhou, Y., Damsky, C.H., and Fisher, S.J. 1997. Preeclampsia is associated with failure of human cytotrophoblasts to mimic a vascular adhesion phenotype. J. Clin. Invest. 99:2152-2164.

42. Iruela-Arispe, M.L. 1997. Normal placentation: a tale that requires an epithelial-to-endothelial conversion [comment]. J. Clin. Invest. 99:2057-2058.

43. Otani, A., Takagi, H., Suzuma, K., and Honda, Y. 1998. Angiotensin II potentiates vascular endothelial growth factor-induced angiogenic activity in retinal microcapillary endothelial cells. Circ. Res. 82:619-628. 